\title{
Bestimmung des Wassers in hygroskopischen Substanzen.
}

\author{
Von \\ Paul Jannasch und James Locke. \\ Nachträgliche Mitteilung.
}

Eine kleine Abänderung des in der voranstehenden Abhandlung beschriebenen Apparates gestattet das Wasser auf eine sehr einfache und genaue Weise in hygroskopischen Körpern zu bestimmen. Die von uns zu diesem Zwecke benutzte Einrichtung wird durch die beifolgende Abbildung leicht verständlich sein:

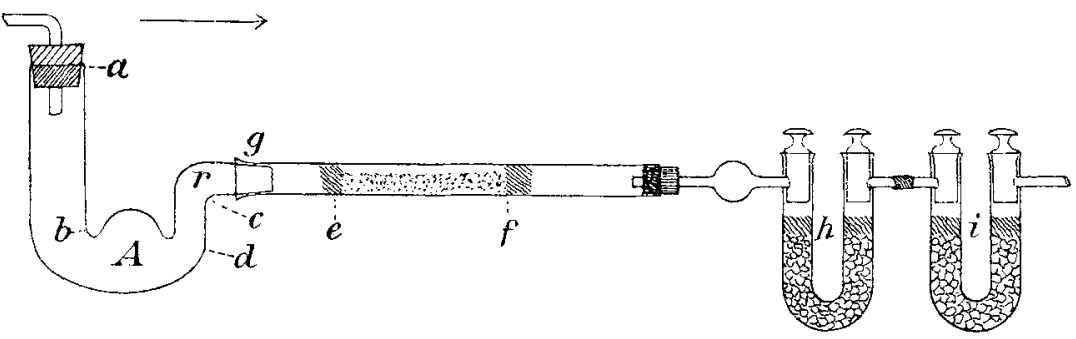

Der Schenkel $a b$ des dreifach gebogenen und in der Mitte teilweise aufgeblasenen Substanzrohres aus Kaliglas hat eine Länge von $6 \mathrm{~cm}$ bei einer Weite von $1.2 \mathrm{~cm}$ im Lichten, während $c d 2 \mathrm{~cm}$ lang ist. Der Inhalt des Gefälses $A$ beträgt $25 \mathrm{ccm}$. Bei $g$ ist das Rohr $r$ luftdicht eingeschliffen, und besonders möge man beachten, dafs sich $a b$ bei $b$ nicht verengt, um dadurch ein glattes und vollständiges Einfüllen der Substanz zu erreichen. Zwischen $e$ und $f$ liegt eine $5 \mathrm{~cm}$ lange Schicht Bleioxyd, durch Glaswolle auf beiden Seiten zusammengehalten.

Nachdem man alle Feuchtigkeit aus dem im Ansatzrohr befindlichen Bleioxyd durch Erhitzen in einem trocknen Luftstrome ausgetrieben hat, schliefst man dasselbe nach dem Erkalten einstweilen ab. Nun wird die Substanz zunächst zwischen Flielspapier möglichst gut abgeprefst und alsdann schnell in das bereits früher für sich gewogene Gefäls A hineingebracht, mit den Stöpseln wieder verschlossen und von neuem gewogen, worauf man durch dasselbe von einem Gasometer aus einen völlig getrockneten Luftstrom hinüberleitet und von 5 zu 5 Minuten die Wägung kontrolliert bis zu einem unveränderlichen Gewichte des Apparates. Im Verlaufe von 15 bis 20 Minuten nimmt das Gewicht der Substanz nicht mehr ab, und es darf dann dieselbe als lufttrocken angesehen werden. 
Indem man weiterhin das Schliffende g der Bleioxydröhre verschlossen hält, verbindet man das andere Ende derselben mit den Chlorcalciumröhren. Unmittelbar hierauf schüttet man zu der Substanz in $A$ die 6 fache Menge ihres Gewichtes an frisch getrocknetem Bleioxyd und mengt durch vorsichtiges Schütteln und Klopfen auf die Handfläche so gut wie möglich. Jetzt erübrigt nur noch das so beschickte Gefäls rasch mit den bereit stehenden Apparatenteilen in Verbindung zu bringen und das chemisch gebundene Wasser durch Erhitzen im Gasstrome etc. auszutreiben. Man bedient sich hierzu einer höchstens zollhohen, beweglichen Flamme und richtet vor allem sein Augenmerk darauf, dafs sich dabei die Temperatur nicht $\mathrm{zu}$ hoch steigert, damit das Glas nicht gleichzeitig angegriffen wird.

Das Wasser aus hygroskopischen Substanzen, wie Calciumchlorid, Magnesiumchlorid, Thoriumbromid ${ }^{1}$ etc. ist in Wirklichkeit bei relativ niederen Hitzegraden vollständig austreibbar. Durchschnittlich yelang uns solches unter den hier angegebenen Bedingungen in etwa 15-30 Minuten. Die bei dem Erhitzen von Halogenen gleichzeitig entweichenden Säuremengen werden von dem überschüssigen Bleioxyd vollkommen sicher zurückgehalten. Unser im obigen beschriebener Apparat besitzt den grofsen Vorzug, dals seine Einzelteile rasch auseinandernehmbar, verschliefsbar und ebenso schnell wieder zusammenfügbar sind, wodurch eine Einwirkung der feuchten Luft auf die Substanz nach Möglichkeit ausgeschlossen erscheint.

Heidelberg, Unirersitätslaboratorium in Februar 1594.

Bei der Redaktion eingegangen am 7. Februar 1894.

${ }^{1}$ Diese Zeitschr. 5, 283.

\section{Berichtigung. \\ Von P. Jannasch.}

Im vorigen Hefte dieser Zeitschrift Seite 1 berichtet Herr C. Böttivaer über eine neue sehr vorteilhafte Vorschrift, reine Thorerde zu gewinnen. In Beziehung hierauf möchte ich nachstehend darauf aufmerksam machen, dafs ich diese Methode zusammen mit den Herren Janes Locke und Joseph Lesnisky schon früher ${ }^{1}$ zur Darstellung grölserer Mengen reiner Thorerde, aus welcher wir damals ein schön krystallisierendes Bromid und Jodid erhielten, angewandt habe. Unsere Arbeit über Thoriumderivate wird fortgesetzt.

Heidelberg, Universitätslaborat., Februar 1894.

Bei der Redaktion eingegangen am 27. Februar 1894.

${ }^{1}$ Diese Zeitschrift $5,285$. 